\title{
Assessing Effects of Challenge-Based Instruction on Conceptual Understand- ing In Heat Transfer
}

\section{Christopher Cirenza, Virginia Tech}

Christopher Cirenza is a second year graduate student at Virginia Tech pursuing his Masters degree in Mechanical Engineering. His research interests include designing and implementing workshops for the undergraduate heat transfer class, calibrating high-temperature heat flux sensors, and screen-printing inexpensive thin film heat flux sensors. He received his Bachelors degree in Physics at Davidson College in 2013.

Dr. Thomas E. Diller, Virginia Tech 


\title{
Assessing Effects of Challenge-Based Instruction on Conceptual Understanding in Heat Transfer
}

\author{
Christopher F. Cirenza, Thomas E. Diller, Christopher B. Williams \\ Department of Mechanical Engineering, Virginia Tech, Blacksburg, VA, 24061, USA
}

\begin{abstract}
Unlike disciplines such as mechanics, where the concepts being taught can be easily seen in the movement of objects in everyday life, heat transfer lacks a visual element to guide conceptual understanding through observation. Traditional lecture style courses in the field of heat transfer are limited in how well they can convey certain difficult concepts. While they stress important ideas such as setting up control volumes and energy balances, they do not do a good job helping students distinguish between the three modes of heat transfer in real world problems (conduction, convection, and radiation), nor can they offer physical representations of problems to allow students to feel heat transfer taking place in different situations. This results in a lack of understanding of the underlying concepts of heat transfer, which is vital as it helps build a foundation from which to work and advance one's thinking.

As a way of overcoming this obstacle, challenge-based workshops were designed and given to a junior level heat transfer class at the authors' institution. The hands-on workshops allowed the students to feel and observe heat transfer via the physical testing apparatus, heat flux sensors and temperature sensors that provided real-time data. These instruments, coupled with the open-ended, challenge-based pedagogy, provided opportunities for students to explore the differences between heat and temperature.

This study examines the effectiveness of these hands-on, challenge-based workshops to improve junior-level heat transfer students' conceptual understanding of heat and temperature. The conceptual knowledge of the students was assessed through a concept inventory test given at both the beginning and the end of the course. These results were compared to those of a control group of students who took the traditional lecture class without the workshops.

The results from the concept inventory yield a significant difference between the total scores of the two groups (experimental and control) as well as certain individual questions. The questions showing significant improvement can be linked directly to workshops conveying the concepts stressed by those questions and include: the difference between heat flow and feeling a temperature difference, effect of surface properties on thermal radiation, and heat transfer in internal flow. Future work entails (i) identifying the concepts in heat transfer that are most important for students to grasp in order to understand the fundamentals of the discipline and (ii) investigating additional ways to evaluate students' conceptual knowledge. The workshops will be restructured to best convey the concepts in a manner easily understood by someone with little or no experience in the field of heat transfer.
\end{abstract}

\section{Introduction}

Heat transfer is part of the core of all Mechanical Engineering curricula, and its concepts can be found throughout science curricula. The concepts of heat and work were developed many 
years ago to explain and solve real physical problems such as the temperature increase experienced in gun boring and how to use steam to pump water from the coal mines in England. Its relevance continues today as the world learns to power society with the least impact on the environment. Whenever energy production or use is discussed, heat transfer processes are integral to the efficiency of the systems.

Given the importance of heat transfer, it is most troubling that recent research shows that students have a limited understanding of heat transfer principles even after the completion of one or more heat transfer courses ${ }^{1}$. Specifically, students have shown (i) a significant lack of conceptual understanding of heat transfer principles, (ii) an inability to transfer knowledge to subsequent courses and out-of-context problems, and (iii) an insufficient transformation from novice to "competent practitioner."

Despite completing several courses in thermal and transport sciences, a significant number of students have misconceptions about simple heat transfer processes ${ }^{2,3,4}$. Through the development of the "Thermal and Transport Concept Inventory" (TTCI) test $\mathrm{t}^{5}$, it has been observed that students possessed "robust misconceptions" about the differences between

- heat, energy and temperature,

- rate and amount of transfer (e.g., heat transfer, momentum transfer, mass transfer), and

- $\quad$ steady-state and equilibrium processes ${ }^{6}$.

In their experiments with Chemical Engineering senior students, it was found that one-third to one-half of the students had misconceptions about these concepts as recorded by the TTCI ${ }^{7}$ Similarly, in a preliminary experiment at the author's institution, wherein two TTCI questions were administered at the start and at the end of the Mechanical Engineering junior-level heat transfer course, resulted in at least half of the students missing some of these concepts - with no substantial improvement in the post-test.

\section{Background and Rationale}

Although the problem of student misconceptions has been clearly identified, an accepted pedagogical method to address these learning deficiencies has not yet been demonstrated. As a step toward addressing this gap, the authors propose an approach to heat transfer education that is centered around hands-on, challenge-based workshops (CBW) that promote discovery and conceptual connections to observed and measured physical phenomena.

Inductive pedagogies such as $\mathrm{CBW}$ are centered in student engagement. A survey of neurological and psychological research found strong support for these approaches, specifically showing that (i) students understood information better when they were forced to link it to their existing cognitive structures, (ii) students were more motivated to learn when they could see the potential for impact, (iii) there was a greater chance of knowledge transfer, and (iv) students' problem-solving skills were improved ${ }^{8}$. Conversely, the deductive learning mode does not reflect what we know about how people learn - following the constructivist learning theory, it is known that students form knowledge representations of new information by building on their previous knowledge and experiences ${ }^{9}$. If the new information has few connections to what they already know, learning will not occur nor will students be motivated to learn ${ }^{10}$. Thus, effective instruction must provide experiences in which students actively construct knowledge by adjusting, rejecting, or modifying their prior beliefs and understanding based on their experiences $^{11}$. Deductive instruction does not facilitate this mode of learning; its "skill-and- 
drill” approach allows students to approach learning passively, and does not challenge them to modify their prior understanding.

The authors' CBW approach is grounded in an existing pedagogy that blends inductive and deductive processes: Challenge-Based Instruction (CBI). CBI begins first with an inquiry or challenge (i.e., a question to be answered or a hypothesis to be tested). Following the principles of the Legacy Cycle of instruction, the students are then (i) asked to formulate their initial thoughts, (ii) receive expert perspectives, (iii) research and revise their solution to the challenge, and finally, (iv) present a final conclusion via presentation, report, or examination ${ }^{12}$. This cycle presents a blended inductive and deductive mode to instruction: the need for learning is motivated by an authentic problem; the challenge causes the students to continuously iterate their conceptual understanding of the domain by consulting the expert (through small lectures), and discussions with their teammates. CBI modules ${ }^{13}$ were created ${ }^{14}$ with support from NSF for a variety of topics in Bioengineering ${ }^{15}$. The method was shown to improve students' performance with open-ended problems ${ }^{16,17,18}$. Inquiry-based learning approaches, such as CBI, have been found to be "more effective than traditional science instruction at improving academic achievement, and the development of thinking, problem-solving and laboratory skills" enhance understanding of critical engineering concepts ${ }^{19,20}$.

A key facet of the CBW approach in heat transfer instruction is the integration of handson workshops into the existing course. The integration of hands-on activities into courses has shown significant learning gains for students across several domains. Faculty have used interactive learning in small groups with hands-on demonstrations to enhance fluids and heat transfer learning in the Chemical Engineering curriculum ${ }^{21,22,23,24}$. RPI has instituted mobile studios, consisting of a suite of instruments that are connected to PC's via USB for observing and testing electrical theories ${ }^{25}$. A similar approach (TEAL) has been instituted at MIT for freshmen physics classes with positive results ${ }^{26}$. Virginia Tech has created a "lab-in-a-box", which is an inexpensive set of instruments and a bread-board to allow students to perform electronic experiments themselves ${ }^{27}$.

The heat transfer workshops in the current study are modeled after the Challenge-Based Instruction (CBI) pedagogy and are designed specifically to target students' common heat transfer misconceptions. The workshops are heavily focused in providing hands-on experiences and allowing students to explore connections between theory and the physical world. As such, the workshops feature state-of-the-art sensors that measure both temperature and heat flux (heat transfer per area). By using these sensors, students are able to physically explore abstract concepts such as thermal energy and heat transfer and thus facilitate learning through the active reconfiguration of their cognitive structure.

In this paper, the authors present the CBW concept, describe its implementation, and report on the results of the assessment of the $\mathrm{CBW}$ on student learning. It was hypothesized that performing simultaneous temperature and heat flux measurements in the context of carefully designed challenge-based learning experiences would (i) improve students' conceptual understanding, (ii) improve their problem-solving abilities, and (iii) improve their ability to transfer knowledge to other courses and contexts. 


\section{Challenge-Based Workshops Description}

This study examined the effect of implementing 12 CBW's into a section of the junior level heat transfer class at the authors' institution. The workshops consisted of simple experiments involving the use of thermocouples and heat flux gauges.

The authors implemented CBW in a junior-level heat transfer class at a large land-grant university. In addition to the two lecture-based meetings, students attended a workshop section during the third meeting of the week. Unlike traditional lab classes, CBWs are given to the students in a structured format that includes a challenge question and five step approach to guide the students in the direction of both solving the challenge question and understanding the underlying concepts. The challenge every week consisted of a hypothetical scenario intended to make the students imagine they were engineers working in industry trying to solve a problem for their employer.

Following the CBI technique, students work to solve the challenge question via research and experimentation through a five step process:

[1] The first step was to generate ideas about the problem. The students were to establish an experimental plan to answer the challenge question. This step always included questions intended to point the students in the right direction and a hypothesis for them to predict what was going to happen.

[2] Step two provided some background information to the students which related to the challenge question they were attempting to solve. Pertinent equations were provided as well as some description of how they were to be used.

[3] In Step three, the students were asked to show which equations they were going to actually use and how they were going to perform their experiment. This usually involved questions relating to how they were going to use their heat flux sensors and thermocouples.

[4] Step four involved the crux of the experiment. Some instructions for how they were to use the data acquisition software were provided along with instructions for how to run the experiment. The students were then asked to evaluate the results of their experiment by solving for certain variables using the data they collected and then answering the challenge question posed to them at the start. Many of their results included graphs that they could both see in real time and examine after the data was taken to assist them in understanding what was physically happening.

[5] Step five was for reflection and included questions asking about the concepts that were stressed during the workshop and was intended to gauge what the students learned throughout the process.

Each workshop was intended to address any misconceptions associated with the specific topic at hand. The workshop topics were chosen to be those presented in the lectures the following week. This approach provided students the opportunity to gain physical experiences with heat transfer phenomena first as a means for motivating their learning of the theoretical principles and relationships. A list of the workshop topics in order of the weeks they were given is presented in Table 1. 
Table 1: Summary of Workshops for Each Week

\begin{tabular}{|c|c|}
\hline Week & Topic Covered in Workshop \\
\hline 1 & $\begin{array}{l}\text { Introduction to software, thermocouples, and heat flux sensors. Conduction heat } \\
\text { transfer for materials of different thermal properties. }\end{array}$ \\
\hline 2 & How fins affect convective heat transfer, convective coefficient. \\
\hline 3 & Understand transient heat transfer- how heat flux and temperature change with time. \\
\hline 4 & $\begin{array}{l}\text { Work more with transient heat transfer and understand thermal resistance and link it to } \\
\text { conduction. Semi-infinite materials. }\end{array}$ \\
\hline 5 & Boundary layers and how they affect convective heat transfer. \\
\hline 6 & Apply ideas of convective heat transfer to internal flow. \\
\hline 7 & Internal flow part 2: overall heat transfer coefficient. \\
\hline 8 & Mass transfer process and relationship of heat and mass transfer. \\
\hline 9 & Computer simulation of a heat exchanger. \\
\hline 10 & Radiant heat transfer, view factors, emissivity and absorptivity. \\
\hline 11 & Radiation part 2: gray bodies and radiosity. \\
\hline 12 & Use thermal camera to look at experiments from previous workshops. \\
\hline
\end{tabular}

Workshop 2 is presented in detail here to provide an example of CBW. The objective of this workshop was for the students to learn what a fin is and how it affects heat transfer. In this workshop, the students were introduced to the idea of heat transfer coefficients. The challenge presented was to determine the convective coefficient, overall heat transfer, and efficiency of given fin. Provided for the students was piece of metal heated at the base to act as a fin, a fan with low and high settings to provide different heat transfer coefficients, thermocouples and a heat flux sensor attached to the fin, and data software and instructions on how to run the experiment.

Step 1: The students were asked to generate ideas about what a fin is, how it works, and what purpose it provides. They were asked questions to help lead them in the right direction.

Step 2: The students were provided information about fins and the relevant equations associated with them. All of the terms in the equation were provided. they have.

Step 3: The students then revised their earlier ideas about fins with the new information

Step 4: The experiment was conducted by the students. In this particular workshop, they created low and high fan air speeds on the fin and watched the plots of temperature across it. They then calculated relevant values and used the heat flux values to calculate convective coefficients, total heat transfer, and efficiencies.

Step 5: For the final step, the students answered reflective questions related to what they learned. They were asked general questions about fins and how their performance changes based on convective coefficients.

The goal of this workshop was for the students to learn the basics of convective and conductive heat transfer and how they are related. The unique challenge-based and hands-on approach is implemented. They entered the workshop with no preconceived notions of convective heat transfer or fins because they had not been taught the material in lecture yet. The main challenge, therefore, was to learn how fins physically work. Using the heat flux sensor combined with thermocouples and doing some calculations gave them physical experience with heat transfer coefficients and the basics of convection. Most importantly perhaps, this workshop gave them the opportunity to actually put their hands on the fin and feel the heat transfer from 
the fin's base to its tip. This, combined with real time plots, provided a new and innovative learning experience for fin heat transfer.

\section{Assessment Methodology}

In order to assess the effect of CBW on students' conceptual understanding of heat transfer concepts, two groups of students were compared - a control group (58 students took the traditional heat transfer course) and an experimental group (68 students that engaged in the CBW intervention). The control section had a 50 minute lecture three times a week; the experimental section had the same 50 minute lecture for the first two days but an hour and fifteen minute workshop was supplemented for the third lecture. Aside from the workshops, all other aspects of the two classes were the same including instructor, tests, and weekly quizzes and homework.

The experimental section was split into three groups of about 20 students so they could have more individualized attention during the workshops. Within those groups, students were split into teams of two and three to perform the workshops so that each student could touch the materials and feel the heat transfer processes first hand.

The workshops all used common materials combined with state-of-the-art sensors and data acquisition software. Each workshop was designed to highlight specific topics in the field of heat transfer and convey the difficult concept in a manner to be easily understood by the students. The workshops focused on these six concepts, which are presented below in Table 2 .

Table 2: Important heat transfer concepts.

\begin{tabular}{|l|l|}
\hline Concept Number & Concept \\
\hline 1 & Heat transfer is inversely proportional to thermal resistance \\
\hline 2 & Heat transfer requires a temperature difference (source and sink) \\
\hline 3 & Temperature change requires an energy transfer \\
\hline 4 & Energy balance must be satisfied (parallel and series pathways) \\
\hline 5 & Fluid flow carries thermal energy while it transfers by conduction \\
\hline 6 & Radiation is purely a surface phenomenon with no medium required \\
\hline
\end{tabular}

In order to evaluate the effect the workshops had on the students, a concept inventory test was given to them at the beginning and end of the semester. The pretest featured five questions from the TTCI and was given not only to compare against a post-test, but to ensure that the control and experimental groups' understanding at the beginning of the study could be considered equivalent. At the end of the semester, the entire 19 question TTCI was given to each section to see if the workshops played a role in helping the students better understand the basic concepts in heat transfer. The questions were taken from the Heat Transfer section of the "Thermal and Transport Concept Inventory" by Ron L. Miller, the "AIChE Concept Warehouse," and the authors.

JMP 11, a statistical analysis software package, was used to examine statistical differences between the performances of the two groups of students. Statistically significant differences were assumed at a significance level $(\alpha)$ of 0.05 . 


\section{Assessment Results}

Results from the pre-test showed statistical difference between the experimental and control groups on the overall quiz, but no significant difference between the groups for any of the five questions individually. The overall averages and standard deviations on the tests were $57.37 \%$ and $0.29 \%$ for the control group and $71.06 \%$ and $0.23 \%$ for the experimental group respectively. Since the initial quiz was only 5 questions, the difference in the overall scores could be attributed to a type 1 error. As class assignments were made at random, it can be assumed that the two sections started off without any advantages or prior knowledge regarding heat transfer concepts.

The results from the 19-question concept inventory given at the end of the semester show a statistically significant difference in overall scores between the two sections and for certain individual questions. The overall averages and standard deviation on the tests were $51.90 \%$ and $0.18 \%$ for the control group and $61.80 \%$ and $0.21 \%$ for the experimental group respectively. A Wilcoxon ranked sum test was performed and revealed that the difference in the overall scores was statistically significant. The mean results for each group (experimental and control) with error bars are shown in Figure 1. The questions have been split into six categories corresponding to the concepts listed in Table 2. The experimental section scored higher on 17 out of the 19 questions as compared to the control group. Of those 17 questions, 10 yielded a percent difference greater than 10 between the two classes and 3 questions yielded a percent difference greater than 20. The questions showing statistically significant differences were 1, 10, 16, and 17. Question 1 is a very general heat and temperature question which falls under concepts 1, 2, and 3 from the list displayed in Table 2. Question 10 has to do with radiation and falls under concept 6. Questions 16 and 17 concern internal flow which link directly to concept 5.

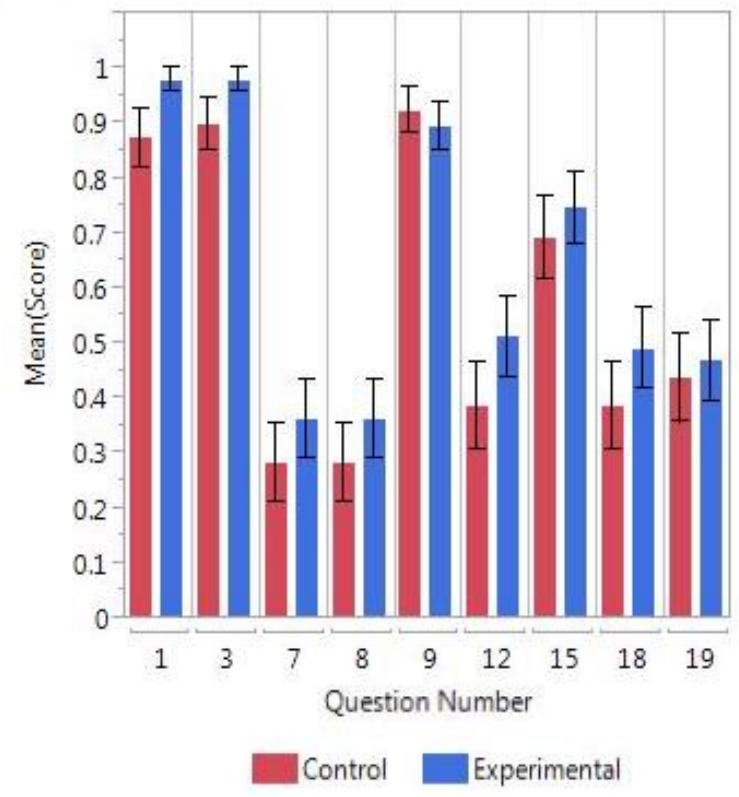

Concept 1: Heat Transfer and Thermal Resistance.

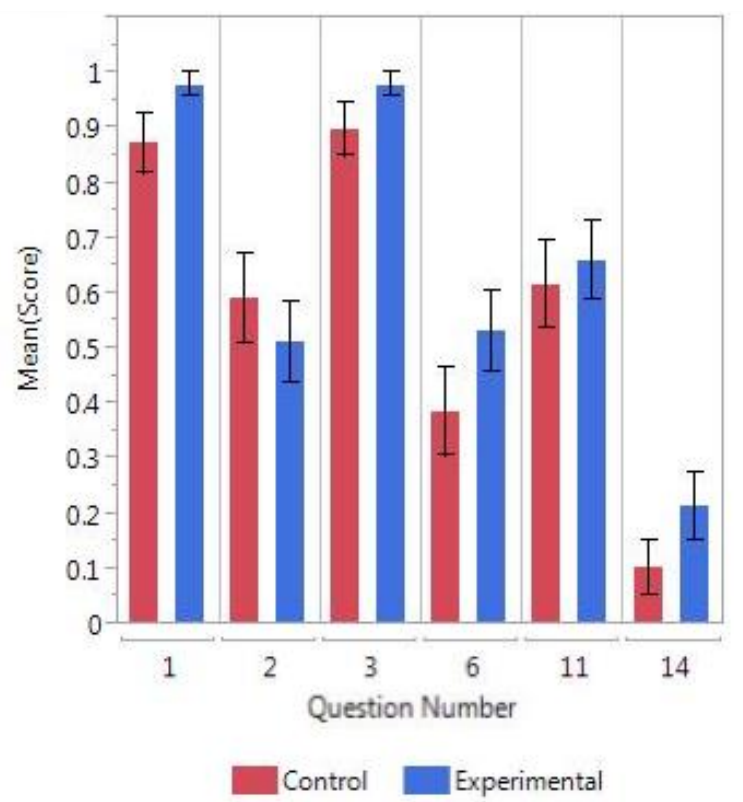

Concept 2: Heat Source and Sink 


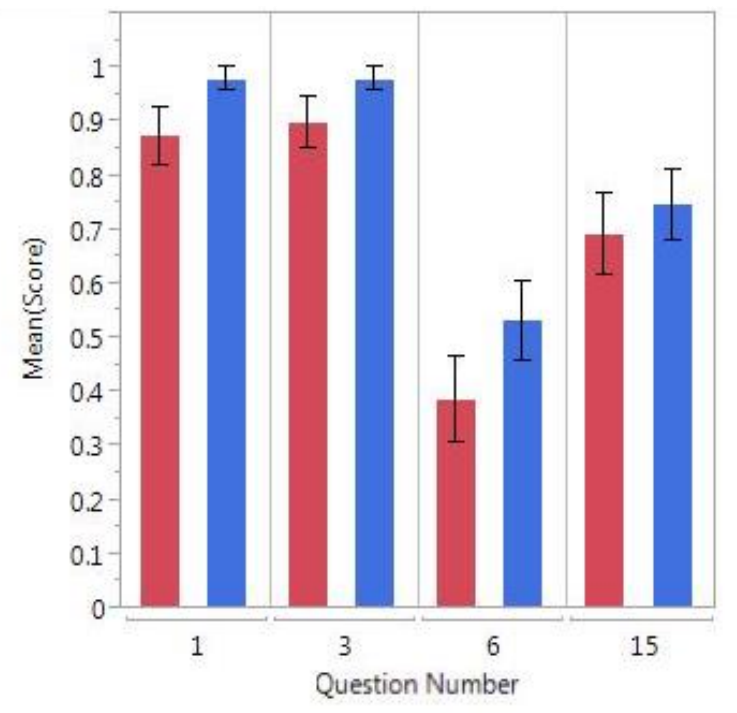

Control

Experimental

Concept 3: Temperature Change/ Energy Transfer

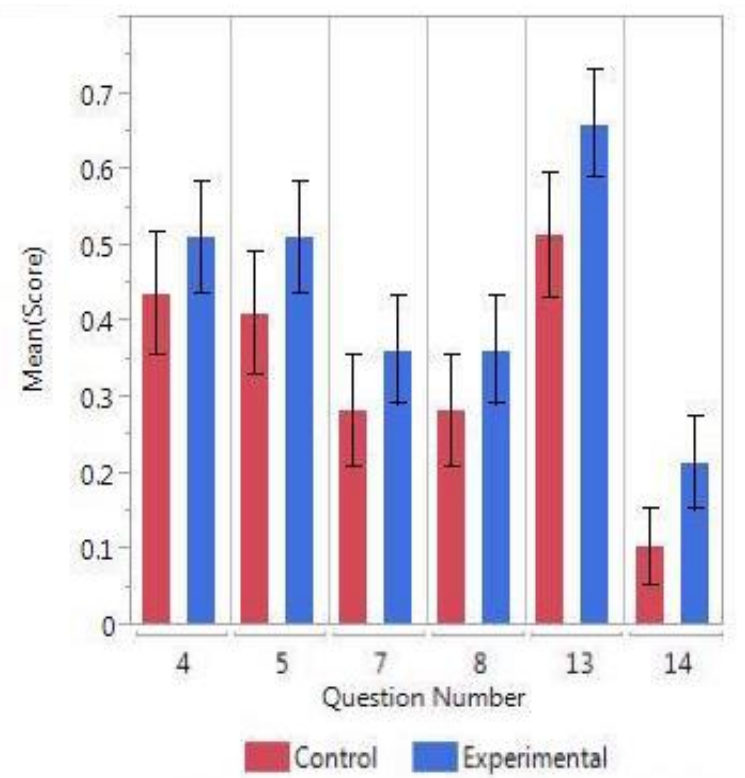

Concept 4: Satisfy Energy Balance

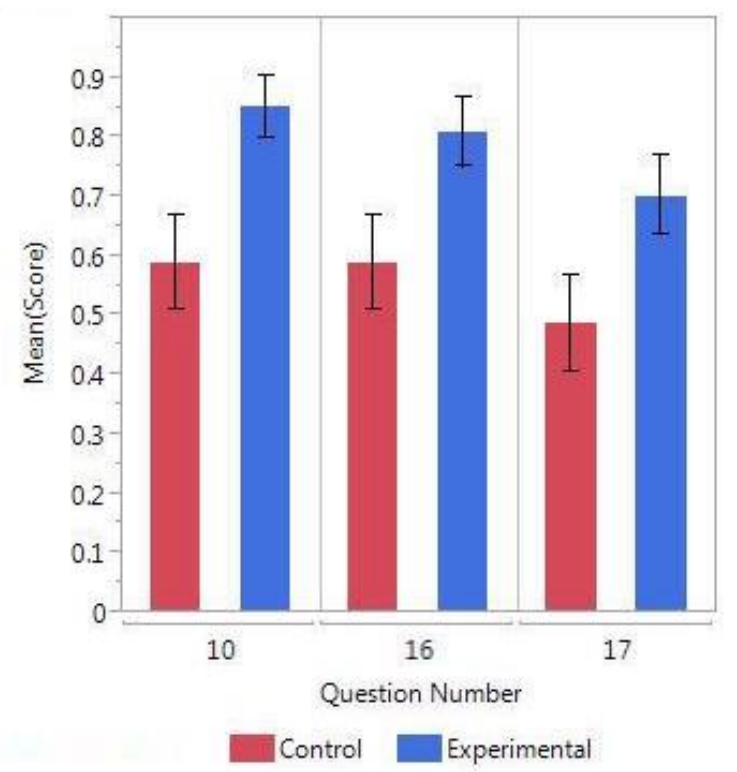

Concepts 5 and 6: Fluid Flow and Radiation

Figure 1: Results from final 19-question concept inventory split into the six different concepts they tested.

Question 1 tested the concept of temperature vs heat and energy by asking why a tile floor feels colder than a carpeted floor. The reason for the discrepancy in scores directly links back to the fourth workshop of the semester where the students had to feel the difference between a steel plate and plastic plate and watch how the surface temperature and heat flux 
responded over time. This workshop allowed the students to directly feel and see in real time how heat transfer was occurring in the plates.

Question 10 tested the concept of radiation giving emissivity and reflectivity values of two different surfaces and asking which one feels warmer when a person is close to them. While 85 percent of the students in the experimental class answered this correctly, only 59 percent of the control group got it right. This question links directly to Workshop 10 in which the students got to feel and measure the difference in radiation from heated black and gray plates and see how the heat flux changed on different surfaces right above the plates. Once again, the higher scores from this question can be attributed to the fact that the students were able to directly feel differences in radiation for the different emissivities.

The last questions that showed statistically significant differences were 16 and 17 and had to do with heat transfer in a heated pipe maintained at a constant temperature hotter than the incoming water. The two questions asked what would happen to the average temperature of the water at the exit and overall heat transfer to the water respectively if the mass flow rate was doubled. During the semester, there were two back-to-back workshops dealing with internal flow in a pipe. In the first workshop, the students measured the heat flux and temperature on the inner and outer surfaces of a metal pipe being cooled on the outside by a fan and having hot air flow through it. The students used their measurements to determine the inner and outer heat transfer coefficients at the beginning and end of the pipe and determine how long the pipe needed to be to cool the air to a certain temperature. In the second workshop, the students used the same setup to solve the same challenge but measured the temperature at six inch increments down the length of the pipe. The fundamental concepts of convective heat transfer in a pipe were covered by feeling the temperature down the length of the pipe (which the experimental section did). Actual measurements of heat flux and temperature showed what was physically happening inside and outside the pipe in real time. This gave the students a chance to not only see how the temperature changed along the length, but the heat flux as well. The use of heat flux gages allowed the students to see exactly how much heat was being transferred from the warm air at a given spot at a given time, which is a much more abstract concept than just seeing and feeling the temperature distributions.

Aside from the concept inventory scores, it is worth looking at how the students performed in the class in general based on their quiz and test scores. Unlike the concept inventory scores, the grades on the quizzes and tests showed no significant difference between the experimental and the control group. Certain test questions were even intended to focus more on the fundamental principles than simply solving problems, but the scores on such questions failed to show any significant difference between the two sections.

A survey was given to the students at the end of the semester to gauge what they thought of the workshops from a qualitative standpoint. Looking at the survey results as a whole, the general consensus was positive. Many students mentioned the benefit of being able to see and feel the modes of heat transfer to apply the concepts they learned in class into physical experiments. Students felt they were able to remember the actual workshops better than the traditional lectures themselves. They also pointed out the benefit of being guided through the workshops by the TA's and they liked how the workshops related to real-world applications.

Looking at what the students disliked about the workshops, the most common responses pointed to the length of the workshops. Almost all of the students mentioned that they felt rushed most of the times to answer all the questions and that the workshops sometimes ran over the allotted time. They also pointed out that some of the number crunching was tedious and 
excessive when they were required to calculate values based on their measurements. Many students also mentioned how they would sometimes get bad or unreasonable values from their data acquisition. This caused them to try and retake the data or to be confused by what was physically happening.

The students were also asked to list the specific workshops they liked the most and which ones they liked the least. Going back to table 1, the workshops that the students pointed to as the ones they liked the most were workshop 2 on external fins, workshops 6 and 7 on internal flow, and workshop 8 on evaporation and mass transfer. The only workshop that received overwhelmingly negative reviews was workshop 9. This workshop was different from all the other ones in that it did not have a physical setup. It was simply a computer animation of a heat exchanger and the students seemed to have a lot of trouble getting the program to do what they wanted.

\section{Conclusions}

Overall the hands-on, challenge-based workshops did a good job addressing the main misconceptions in heat transfer and helped the students to improve on their understanding of the concepts. The workshops failed, however, in getting the students to apply the concepts to solving problems on their quizzes and tests. While the results on the concept inventory showed a strong statistical difference between the experimental and control groups, neither the quiz grades, test grades, nor final grades showed a significant difference. The students who took the workshops seemed to be unable to translate the concepts they learned into solving actual heat transfer problems.

Current work involves restructuring the workshops to try and get the students to meld conceptual understanding with problem solving skills. The workshops are being shortened into hour-long sessions that will focus much more on explanations of the data and how certain plots make sense with what is physically happening. The entire data acquisition will be pre-recorded so the students will not have to worry about acquiring good values. However, they will still perform the experiment as if they are taking the data in order to keep the benefit of feeling the experiment as the plots are being displayed. The workshops will run much smoother because they will not require any real-time measurements. As a result, the students will have more time to think about the concepts and how they relate to the experiment at hand. The workshops will also be included in addition to the three-lecture a week course instead of as a substitute for one of the lectures. The goal now is to get the students to better understand the concepts at work in the workshops and help the students to apply the concepts to improve on their quizzes and tests and the class as a whole.

\section{Acknowledgements}

This material is based upon work supported by the National Science Foundation under Grant No. \#1254006. Any opinions, findings, and conclusions or recommendations expressed in this material are those of the author(s) and do not necessarily reflect the views of the National Science Foundation. 


\section{References}

${ }^{1}$ Nottis, K. E. K., M. Prince, M. Vigenat, S. Nelson, and K. Hartsock, 2009, “Undergraduate Student's Understanding of Heat, Temperature and Radiation," Northeastern Educational Research Association Annual Conference Proceedings.

${ }^{2}$ Miller, R.L., R. A. Streveler, and B. M. Olds, 2007, "Use of Concept Inventories to Identify Misconceptions in Thermal Sciences," Proceedings of the 2nd International Conference on Engineering Education \& Training, Kuwait City, Kuwait, April 9-11.

${ }^{3}$ Self, B. P., R. L. Miller, A. Kean, T. J. Moore, T. Ogletree, and F. Schrieber, 2008, "Important Student Misconceptions in Mechanics and Thermal Science: Identification using Model-eliciting Activities," ASEE/IEEE Frontiers in Education Conference, Saratoga Springs, NY.

${ }^{4}$ Jacobi, A., J. K. Martin, J. Mitchell, and T. Newell, 2003, "A Concept Inventory for Heat Transfer," Proceedings Frontiers in Education Conference, Boulder CO, USA.

${ }^{5}$ Streveler, R. A., R. L. Miller, M. A. Nelson, M. R. Geist, and B. M. Olds, 2008a, "Developing an Instrument to Measure Engineering Students Misconceptions in Thermal and Transport Science," Journal of Engineering Education.

${ }^{6}$ Miller, R. L., R.A. Streveler, B.M. Olds, M.T.H. Chi, M.A. Nelson, and M.R. Geist, 2006, "Misconceptions about Rate Processes: Preliminary Evidence for the Importance of Emergent Conceptual Schemas in Thermal and Transport Sciences," Proceedings of the American Society for Engineering Education Annual Conference, Chicago, Illinois, June 18-21.

${ }^{7}$ Streveler, R. A., Litzinger, T. A., Miller, R. L., and Steif, P. S., 2008b, "Learning Conceptual Knowledge in the Engineering Sciences: Overview and Future Research Directions," Journal of Engineering Education, Vol. 98, pp. 279-294.

${ }^{8}$ Bransford, J.D., A. L. Brown, and R. R. Cocking, eds., 2000, How People Learn: Brain, Mind, Experience, and School. National Academy Press, Washington, D.C.

${ }^{9}$ Pellegrino, J.W., 2006, "Rethinking and redesigning curriculum, instruction and assessment: What contemporary research and theory suggests." A paper commissioned by the National Center on Education and the Economy for the New Commission on the Skills of the American Workforce.

${ }^{10}$ Albanese, M. A. and S. Mitchell, 1993, "Problem-Based Learning: A Review of Literature on its Outcomes and Implementation Issues," Academic Medicine, Vol. 68, pp. 52-81.

${ }^{11}$ Prince, M. J. and R. M. Felder, 2006, "Inductive Teaching and Learning Methods: Definitions, Comparisons, and Research Bases," Journal of Engineering Education, Vol. 95, No. 2, pp. 123-138.

${ }^{12}$ Vanderbilt University, accessed 2009, "Star Legacy Modules," Iris Center for Faculty Enhancement, http://iris.peabody.vanderbilt.edu/hpl/chalcycle.htm.

${ }^{13}$ Barr, R., M. Pandy, A. Petrosino, R. Roselli, S. Brophy, and R. Freeman. 2007. Challenge-based instruction: The VaNTH biomechanics modules. Advances in Engineering Education 1 (1): 1-30.

${ }^{14}$ Roselli, R.J. and S.P. Brophy, 2003, Redesigning a biomechanics course using challenge-based instruction. IEEE Engineering in Medicine and Biology Magazine 22 (4): 66-70.

${ }^{15}$ Martin, T., S. D. Rivale, and K. R. Diller, 2007, "Comparison of Student Learning in Challenge-based and Traditional Instruction in Biomedical Engineering," Annals of Biomedical Engineering., Vol. 35, pp. 1312-23.

${ }^{16}$ Rayne, K., T. Martin, S. Brophy, N.J. Kemp, J.D. Hart, and K.R. Diller. 2006. The development of adaptive expertise in biomedical engineering ethics. Journal of Engineering Education 95 (2): 165173.

${ }^{17}$ Cordray, D. S., T. R. Harris, and S. Klein, 2009, “A Research Synthesis of the Effectiveness, Replicability, and Generality of the VaNTH Challenge-based Instructional Modules in Bioengineering," J. Eng. Education, Vol. 98, pp. 335-348.

${ }^{18}$ Roselli, R.J. and S.P. Brophy, 2006, Effectiveness of challenge-based instruction in biomechanics. Journal of Engineering Education 95 (4): 311-324.

${ }^{19}$ Prince, M. J. and M. Vigeant, 2006, "Using Inquiry-based Activities to Promote Understanding of Critical Engineering Concepts," ASEE Annual Conference, 2006-1379, Chicago, IL.

20 Nottis, K. E. K., M. J. Prince, and M. A. Vigeant, 2009, "Building an understanding of heat transfer concepts in undergraduate chemical engineering courses," US-China Education Review, Vol. 7, No. 2, pp. 1-9. 
${ }^{21}$ Golter, P.B., Van Wie, B.J., Scuderi, P.V., Henderson, T. W., Dueben, R. ., Brown, G.R., and Thomson, 2005, W. J., "Combining Modern Learning Pedagogies in Fluid Mechanics and Heat Transfer, "Chemical Engineering Education, Vol. 39, pp. 280-287.

${ }^{22}$ Van Wie, B. J., Poshusta, J. C., Greenelee, R. D., Brereton, R. A., 1994, “ Fun Ways to Learn Fluid Mechanics and Heat Transfer," Chemical Engineering Education, Vol. 28, pp. 188-192.

${ }^{23}$ Minerick, A., 2009, “A Desktop Experiment Module: Heat Transfer,” ASEE 2009 Annual Conference, Austin, TX.

${ }^{24}$ Abdul, B., Shide, E., Bako, R., Golter, P., Babauta, J., Van Wie, B., and Brown, G., 2009, “An evaluation of Pedagogical Gains in a Fluid Flow Class When Using Desktop Learning Modules in an African University," ASEE 2009 Annual Conference, Honolulu, HW, AC 2009-1122.

${ }^{25}$ Millard, D., Choulikha, M., Berry, F., 2007, "Improving Student Intuition via Rensselaer's New Mobile Studio Pedagogy," ASEE 2007 Annual Conference, Honolulu, HW, June.

${ }^{26}$ Belcher, J., Dourmashkin, P. and Dori, Y., 2004, “Technology Enabled Active Learning (TEAL): Studio Physics at MIT," http://gallery.carnegiefoundation.org/collections/keep/jbelcher.

${ }^{27}$ Clark, R., Jr., Flowers, G. H., Doolittle, P., Meehan, K., and Hendricks, R. W., 2009, "Work in Progress Transitioning Lab-in-a-Box (LiaB0 to the Community College Setting," 39th ASEE/IEEE Frontiers in Education Conference, San Antonio, TX. 